\title{
Factors influencing breastfeeding preparedness among primigravidae attending antenatal clinic, at university of Port Harcourt teaching hospital, Rivers state, Nigeria
}

\author{
Robinson-Bassey G. C. ${ }^{1}$, Frank Maureen D. ${ }^{2 *}$, Iwu Rosemond C. ${ }^{1}$
}

\author{
${ }^{1}$ Department of Nursing Science, Faculty of Clinical Sciences, College of Health Sciences, University of Port Harcourt \\ ${ }^{2}$ Faculty of Nursing, College of Health Sciences, Niger Delta University, Bayelsa State
}

Received: 25 January 2016

Revised: 05 March 2016

Accepted: 07 March 2016

\section{*Correspondence:}

Dr. Frank Maureen D.,

E-mail: maureendikefrank@yahoo.co.uk

Copyright: ( ) the author(s), publisher and licensee Medip Academy. This is an open-access article distributed under the terms of the Creative Commons Attribution Non-Commercial License, which permits unrestricted non-commercial use, distribution, and reproduction in any medium, provided the original work is properly cited.

\begin{abstract}
Background: This is a descriptive survey to determine the factors influencing breast feeding preparedness among primigravidae attending ante natal clinic at University of Port Harcourt Teaching Hospital. Three objectives and one hypothesis were formulated to guide the study.

Methods: A purposive sampling technique was used to select 108 respondents for the study. The instrument used for data collection was a self-structured questionnaire. The validity of the instrument was ascertained while the reliability confirmed through test- re-test which yielded a coefficient of 0.99 which was considered appropriate. Data were analyzed using descriptive statistics while relationship was tested using inferential statistics and results presented in tables.

Results: Findings revealed that only 4 (14.3\%) aged between 24-29 years were "well prepared" to breast feed their babies; others were either "fairly or poorly prepared". Breastfeeding preparedness was also observed to be associated with maternal occupation. The findings showed that the unemployed and petty traders ranked highest in being well prepared, $8.3 \%$ and $12.5 \%$ respectively as compared to their counterparts. Also, result of the study revealed that preparedness is higher among women that had secondary and tertiary education, $61.6 \%$ and $50.1 \%$ respectively.

Conclusions: Based on these findings it was recommended among others that midwives should be involved in appropriate education of expectant mothers especially new ones to help improve breastfeeding preparedness among them; women should be engaged in occupation that allow them enough time to breastfeed and employers should make adequate provisions for breastfeeding mothers in order to encourage them.
\end{abstract}

Keywords: Mothers, Breastfeeding, Preparedness, Primigravidae \& factors

\section{INTRODUCTION}

Prenatal intention to breastfeed has been shown to be a predictor of actual breastfeeding exclusively. Early discussions with health care professionals can help women realize this commitment while exploring the supports and resources they will need to make exclusive breastfeeding a feasible and rewarding process for them, their infants and their family.
Breastfeeding has been recognized as an optimal sole source of nutrition in infancy because breast milk contains special properties that make it superior to the most carefully made home and commercial preparations. ${ }^{1}$ It is associated with improved developmental and social outcomes for an infant.

Breastfeeding is associated with a number of health related benefits among infants, including improved 
nutritional, developmental, immunological, and social outcomes, reduced incidence or severity of diarrhoea and respiratory illnesses. Breastfeeding has also been associated with benefits for the mother as well; women who breastfeed recover faster from childbirth and are at a reduced risk for acute and chronic conditions including cancer, osteoporoses, obesity, reduced risk of postpartum haemorrhage (PPH),ovarian and premenopausal breast cancers. ${ }^{2}$ There is also an economic advantage through birth and population explosion control. ${ }^{1}$

Despite these health benefits, it has been observed that only $54 \%$ of women breastfeed in the early postpartum period. Although an understanding of socio-demographic characteristics, breastfeeding intent, and breastfeeding attitudes can facilitate breastfeeding initiatives. The objectives of this study are to provide a descriptive analysis of the socio-demographic factors influencing breastfeeding intent, among primigravidae presenting to an inner city prenatal clinic and determine if breastfeeding attitudes are associated with breastfeeding intent and socio-demographic variables. Breastfeeding intent was associated with, positive breastfeeding attitudes, higher household incomes, having family, peer, and partner support for breastfeeding, attending breastfeeding classes, and greater years of education. ${ }^{2}$

The World Health Organization (WHO) and the American Academy of Pediatrics (AAP) recommend that mothers breastfeed their infants exclusively for the first 6 months, preferably 1 year, and continue to breastfeed thereafter for up to 2 years. ${ }^{3,4}$ Despite such recommendations and positive outcomes, only $54 \%$ of women breastfeed in the early postpartum period. ${ }^{5}$

Mild breastfeeding challenges like the overwhelming demand to breastfeed exclusively (which they are doing for the first time), lack of confidence, lack of support (families or employers), nipple pain, possible lifestyle changes, bias against breastfeeding such as infants need extra water to be satisfied (which could be due to poor knowledge of breastfeeding), seem to force mothers to give up within the first few weeks of breastfeeding. ${ }^{5}$

Observations have shown that women are highly receptive to health information, as they plan their pregnancy, breastfeeding promotion should also be a part of well-women preconception and inter-conception health care health education to enable them develop their immediate social networks and planning parenting strategies including plans to exclusively breast feed.

This study sought to answer the following questions:

- Does age influence breastfeeding preparedness among primiparae.

- Does educational level and occupation primiparae's preparedness towards breastfeeding.

- Is there any significant relationship between occupation and preparedness.

\section{Purpose of the study}

The purpose of this study is to determine the factors influencing breastfeeding preparedness among primigravidae attending antenatal clinic at University Port Harcourt Teaching Hospital, Rivers State.

\section{METHODS}

This is a descriptive survey determining the factors influencing the breastfeeding preparedness among primigravidae attending antenatal clinic at University of Port Harcourt Teaching Hospital. The study was carried out in the University of Port Harcourt Teaching Hospital (UPTH), Alakahia, Obio-Akpor Local Government Area Rivers State. It is geographically bounded by Aluu, Choba and Rumuosi in the north, south and east respectively. UPTH is a tertiary institution of health care which offers training for both undergraduates and postgraduates of medical and paramedical fields, and health care management of conditions that cannot be handled in the secondary and primary institutions. UPTH is both baby friendly and a 5-star hospital. It has 26 departments including Orthopaedics, Microbiology, Ante-natal, Nursing, Anatomical Pathology, Community Health, Internal medicine, Surgery. The target population was all primigravidae that attended antenatal clinic in UPTH, Alakahia, Port Harcourt throughout the months of June and July, 2012. ${ }^{6}$ A total of 108 primigravidae who were readily accessible at the ante natal clinic were used for the study. A self-structured questionnaire consisting of two sections, A and B was developed for this study. Section A consisted of three items addressing the sociodemographic data and Section B consisted of nine items addressing preparedness towards breastfeeding. Specifically, five items in section B were used to determine how prepared the mothers were towards breastfeeding. The questionnaire was submitted to two experts, an obstetrician and a midwife for evaluation. Their observations and comments were used to make necessary corrections. They thereafter affirmed the content and face validity of the instrument before administering them. In order to establish the reliability of the instrument, a test re-test was carried out with 10 primigravidae drawn from Health Centre in Aluu. The questionnaire was re-administered to the same respondents after a time interval of two weeks. The data obtained was analysed using the Pearson's product Moment Correlation coefficient formular and a coefficient value of 0.99 was obtained which was considered appropriate for the study. The researchers administered the questionnaire to 108 respondents selected for the study on each of the Monday clinic days for the period of the study, all dully completed questionnaires were retrieved immediately on completion on each of the days and $100 \%$ return rate was recorded. Data collected was coded into a spread sheet and analyzed using descriptive statistical measures. Out of the five (5) questions used in determining the level of preparedness among respondents, a score of 5 indicates 
"well prepared", a score of 3 to 4 fairly prepared, that of 1- 2 'poorly prepared", while a score of 0 indicates "not prepared".

In terms of interest to initiate and maintain exclusive breastfeeding respondents who opted to breastfeed for up to six months and continues for 18 - 24 months were adjudged "well prepared"; those who opted for four months and to continue for another 12-18 months were adjudged "fairly prepared" while those who opted for initiating breastfeeding and combining it with formula feed between one to four months post-partum were "poorly prepared" and those not willing to initiate breastfeeding within the first four weeks post-partum were adjudged "not prepared". Consent was obtained from the ethical committee of the hospital used for the study. The purpose of the study was explained to the respondents who were also assured of the confidentiality of all information provided and respondent's anonymity maintained.

\section{RESULTS}

Table 1 showed that out of the 108 respondents 24 $(22.2 \%)$ were aged 20-24years, 28 (25.9\%) were within 25-29 years, $44(40.8 \%)$ within $30-34$ years while $6(5.5 \%)$ each were 35-39 years and 40-44 years respectively. In terms educational status only 4 (3.7\%) of the respondents had informal education, 2 (1.9\%) primary education, $42(38.9 \%)$ secondary education, while 60 $(55.6 \%)$ had tertiary education. As regards occupational status, $24(22.2 \%)$ each belonged to the unemployed and civil servant categories respectively; 18 (16.7\%) were students, $8(7.4 \%)$ were teachers, 16 (14.8\%) petty traders, and others including farmers and professionals made up the remaining $18(16.7 \%)$.

Table 1: Socio-demographic characterization of respondents $(\mathbf{n}=108)$.

\begin{tabular}{|ll|}
\hline Characteristics & Percentage (\%) \\
\hline Age & $24(22.2)$ \\
\hline $20-24$ & $28(25.9)$ \\
\hline $25-29$ & $44(40.8)$ \\
\hline $30-34$ & $6(5.5)$ \\
\hline $35-39$ & $6(5.5)$ \\
\hline $40-44$ & $108(100.0)$ \\
\hline Total & \\
\hline Educational level & $4(3.7)$ \\
\hline Informal & $2(1.9)$ \\
\hline Primary & $42(38.9)$ \\
\hline Secondary & $60(55.6)$ \\
\hline Tertiary & $108(100.0)$ \\
\hline Total & \\
\hline Occupation & $24(22.2)$ \\
\hline Unemployed & $24(22.2)$ \\
\hline Civil servant & $18(16.7)$ \\
\hline Student & $8(7.4)$ \\
\hline Teaching & $16(14.8)$ \\
\hline Petty trader & $18(16.7)$ \\
\hline Others & $108(100.0)$ \\
\hline Total & \\
\hline
\end{tabular}

Table 2: Age of mothers and preparedness towards breastfeeding ( $n=108)$.

\begin{tabular}{|llllll|}
\hline \multirow{2}{*}{ Age of mothers } & \multicolumn{5}{c|}{ Frequency $(\%)$} \\
\hline $20-24$ & Not properly & Poorly prepared & Fairly prepared & Well prepared & Total (\%) \\
\hline $25-29$ & $0(0.0)$ & $8(33.3)$ & $16(66.7)$ & $0(0.0)$ & $24(100)$ \\
\hline $30-34$ & $2(7.14)$ & $8(28.6)$ & $14(50.0)$ & $4(14.3)$ & $28(100)$ \\
\hline $35-39$ & $0(0.0)$ & $18(40.9)$ & $26(59.1)$ & $0(0.0)$ & $44(100)$ \\
\hline $40-44$ & $0(0.0)$ & $4(66.7)$ & $2(33.3)$ & $0(0.0)$ & $6(100)$ \\
\hline
\end{tabular}

Table 3: Level of education of mothers and preparedness towards breastfeeding $(n=108)$.

\begin{tabular}{|llllll|}
\hline \multirow{2}{*}{ Level of education } & Not prepared & Poorly prepared & Fairly prepared & Well prepared & Total (\%) \\
\hline Informal & $0(0.0)$ & $2(50.0)$ & $2(50.0)$ & $0(0.0)$ & $4(100)$ \\
\hline Primary & $0(0.0)$ & $0(0.0)$ & $2(100.0)$ & $0(0.0)$ & $2(100)$ \\
\hline Secondary & $0(0.0)$ & $14(33.4)$ & $26(61.6)$ & $2(4.8)$ & $42(100)$ \\
\hline Tertiary & $2(25.0)$ & $26(43.3)$ & $30(50.1)$ & $2(3.3)$ & $60(100)$ \\
\hline
\end{tabular}

Table 2 showed that $8(33.3 \%)$ of the respondents between the ages of 20-24 were "poorly prepared", and $16(66.7 \%)$ were "fairly prepared", those aged between 25-29 years, only $2(7.14 \%)$ were "not prepared", 8
(28.6\%) were "poorly prepared", $14(50.0 \%)$ of them "fairly prepared" and $4(14.3 \%)$ "well prepared". With regards to those within ages 30-34 years, 18 (40.9\%) were "poorly prepared", $26(59.1 \%)$ were "fairly 
prepared", but none was "well prepared" to breastfeed. For the 35-39 years age group, 2 (33.3\%) were "fairly prepared", and none was "well prepared" for breastfeeding.

Table 3 showed the level of education compared with respondent's preparedness to breastfeed. Out of the 108 respondents, only $2(1.9 \%)$ with primary education were "fairly prepared" to breastfeed. Most of the respondents $60(64.8 \%)$ had tertiary education, of these $2(3.3 \%)$ were "not prepared", 26 (43.3\%) were "poorly prepared", 30 $(50.1 \%)$ "fairly prepared" while $2(3.3 \%)$ were "well prepared".

Table 4: Occupation of mothers and preparedness towards breastfeeding $(n=108)$.

\begin{tabular}{|llllll|}
\hline Occupation & Not prepared & Poorly prepared & Fairly prepared & Well prepared & Total (\%) \\
\hline Unemployed & $0(0.0)$ & $2(8.3)$ & $20(83.4)$ & $2(8.3)$ & $24(100)$ \\
\hline Civil servants & $0(0.0)$ & $18(75.0)$ & $6(25.0)$ & $0(0.0)$ & $24(100)$ \\
\hline Students & $0(0.0)$ & $10(55.6)$ & $8(44.4)$ & $0(0.0)$ & $18(100)$ \\
\hline Teaching & $2(25.0)$ & $4(50.0)$ & $2(25.0)$ & $0(0.0)$ & $8(100)$ \\
\hline Petty Trading & $0(0.0)$ & $4(25.0)$ & $10(62.5)$ & $2(12.5)$ & $16(100)$ \\
\hline Others & $0(0.0)$ & $4(22.2)$ & $14(77.8)$ & $0(0.0)$ & $18(100)$ \\
\hline
\end{tabular}

Table 5: Relationship between mother's occupation and breastfeeding preparedness $(\mathrm{n}=108)$.

\begin{tabular}{|lllllll|}
\hline Variable & & \multicolumn{2}{c}{ Breastfeedling preparedness } & Row & $\mathbf{X}^{2}$ \\
\hline Mother's occupation & Not prepared & Poorly properly & Fairly prepared & Well prepared & total \\
\hline Unemployed & 0.44 & 1.78 & 0.12 & 0.34 & 2.68 \\
\hline Civil servant & 0.44 & 10.00 & 0.12 & 1.33 & 11.89 \\
\hline Student & 0.33 & 1.33 & 0.47 & 1.00 & 3.13 \\
\hline Teaching & 22.82 & 0.59 & 0.96 & 1.00 & 25.37 \\
\hline Petty trading & 0.30 & 0.15 & 0.19 & 1.38 & 2.42 \\
\hline Others & 0.33 & 1.33 & 0.03 & 0.34 & 2.03 \\
\hline
\end{tabular}

Table 4 showed that among the unemployed women, 2 $(8.3 \%)$ were poorly prepared', 20 (83.4\%) fairly prepared, while $2(8.3 \%)$ were well prepared" to breastfeed. For those in civil servants category, 18 $(75.0 \%)$ were poorly prepared" and 6 (25.0\%) were ''fairly prepared", but none was ''well prepared'. As regards the students, $10(55.6 \%)$ were "poorly prepared" while $8(44.4 \%)$ were "'fairly prepared" to breastfeed. In terms of occupation, for those teaching, 2 (25.0\%) were "'not prepared", 4 (50.0\%) were "poorly prepared", while $2(25.0 \%)$ were "fairly prepared" for breastfeeding. For petty traders, $4(25.0 \%)$ were "poorly prepared", 10 $(62.5 \%)$, "fairly prepared", while $2(12.5 \%)$ were "well prepared".

Since the calculated $X^{2}$ value 47.52 is greater than the critical value $\mathrm{x}^{2}=25$ at $\mathrm{p}=0.05, \mathrm{df}=15$, the null hypothesis "there is no significant difference between the occupation of mothers and breastfeeding preparedness" is therefore rejected.

\section{Summary}

- Respondents within the age range of 30-34 were more $44(40.8 \%)$ than those in other age ranges

- Respondents with tertiary education were more 60 $(55.6 \%)$, followed by those with secondary 42 $(38.9 \%)$

- Well preparedness was observed among primiparae within the age range of 25-29 and none among respondents within the other age ranges

- Well preparedness was also observed among Primiparae with secondary and tertiary education and none among primary and informal education

- Well preparedness was observed among primiparae who are unemployed or engaged in petty trading while none was observed among women in other various occupations

- Occupation has significant influence on preparedness to breastfeed. 


\section{DISCUSSION}

\section{Mother's age and breastfeeding preparedness}

Findings revealed that a higher percentage of women between the ages of 20-24 (66.7\%) and 30-34 (59.1\%) showed a higher level of preparedness to breastfeed than the other women. This finding is in contrast with other observations which stated that the probability of exclusively breastfeeding up to 4 months was 3.1times higher for children of mothers aged 25 to 29 years, 4-7 times for those between 30 to 34 years compared to women who were less than 25 years old. ${ }^{7}$ This according to them can be attributed to the fact that they want to maintain their physique and also immaturity of mind to carry out the breastfeeding process. Exclusive breastfeeding was $30 \%$ among older women and $17 \%$ among the younger women and that moral norm was the largest predictor of an adolescent mother's breastfeeding intention. ${ }^{8}$ Breast feeders also tend to be older than none or poor bresatfeeders. ${ }^{2}$

This contrasting result could be attributed to the fact that those within this age range are also within the category of the unemployed and students among whom well preparedness was observed.

\section{Mother's educational level and breastfeeding preparedness}

Result of the study revealed that preparedness is higher among women that had secondary and tertiary education, $61.6 \%$ and $50.1 \%$ respectively. This is in agreement with other findings; $(60 \%)$ of their respondents were well educated women and they also practiced exclusive breastfeeding, also low breast feeders had been observed among women with limited breastfeeding information, and that high breast feeders tend to have received more years of formal education. ${ }^{1,2}$ They further stated that, this could be attributed to the fact that well educated mothers are more likely to have access to information regarding breastfeeding and some of its common problems, thus they tend to persevere, continuing breastfeeding longer than others who are less educated ,rather than weaning early.

\section{Mother's occupation and breastfeeding preparedness}

The findings showed that the unemployed and petty traders ranked highest in being well prepared, $8.3 \%$ and $12.5 \%$ respectively as compared to their counterparts. This finding is supported by other findings, which observed that breastfeeding mothers who are overworked cannot breastfeed frequently and long separation from children makes breastfeeding especially exclusive breastfeeding difficult. $^{9}$

\section{Influence of occupation on breastfeeding preparedness among the expectant mothers}

The result showed that the calculated $X^{2}$ value 47.52 is greater than the critical value $=25$ at $\mathrm{p}=0.05, \mathrm{df}=15$, the null hypothesis "there is no significant difference between the occupation of mothers and breastfeeding preparedness" is therefore rejected. This observation was supported by other studies which stated that low breastfeeding rates, have been associated with working full time. ${ }^{10-12}$

\section{Implications for midwifery practice}

Expectant mothers are faced with challenges that may affect breastfeeding adversely. Some women as discovered in the study are not ready to breastfeed for up to six (6) months after birth or longer, and many who wish to stop breastfeeding, do so in the early post-partum period exposing the infant and themselves to illness.

Midwives interact with new expectant mothers in all hospitals, community, homes, churches and mosques. Therefore, nursing interventions are required to improve breastfeeding preparedness. Some of such interventions could be in form of: adequate support and education of expectant mothers especially new ones to help improve breastfeeding preparedness; keeping up to date on best breastfeeding practices ; encouraging mothers to prepare for common breastfeeding challenges such as nipple pain, sleep deprivation and fatigue among others; expectant mothers could also be referred to their fellow women who have had a successful breastfeeding experience and also assess and counsel mothers at risk of attrition and reduce early attrition from breastfeeding.

\section{CONCLUSIONS}

The purpose of this study was to determine the factors influencing breastfeeding preparedness among new expectant mothers attending antenatal clinic at University Port Harcourt Teaching hospital, Rivers State. Three (3) factors namely mother's age, level of education and occupation were studied to determine their influence on breastfeeding preparedness. Inferences drawn from the findings showed that occupation and educational levels influences breastfeeding preparedness.

Poor educational level (informal and primary), results in limited knowledge of breastfeeding, consequently, this negatively affects preparedness towards breastfeeding. This is because adequate or good knowledge of breastfeeding and its importance appears to be synonymous towards breastfeeding. Lack of knowledge and skill might affect preparedness. Occupation affects a woman's preparedness towards breastfeeding. Findings from this study showed that more than half 18 (75.0\%) among the civil servants were poorly prepared to breastfeed. The influence of age on preparedness is dependent on some other factors such as employment status. It is therefore essential that health workers provide adequate information especially for those that are not well educated. Government should encourage the motivating factors towards breastfeeding such as education of women by providing free education as this will help to reduce the negative effects of poor education 
on breast feeding. Employers also, should give support to the fulltime workers such as provision of crèche among others to encourage breastfeeding preparedness among the breast feeding mothers.

\section{Recommendations}

1. Women should be involved in occupations that allow them enough time for breastfeeding.

2. Career women should strike a balance between time for work and time for breastfeeding.

3. Employees should make provision for breastfeeding for nursing mothers, in ways such as providing private halls (for breastfeeding), allowing them to leave work a bit earlier than non-nursing mothers.

4. Health care providers should identify new mothers at early risk of attrition from breastfeeding, provide encouragement and offer unbiased guidance and support to such women to ensure effective preparedness, initiation and continuity of breastfeeding.

Funding: No funding sources Conflict of interest: None declared

Ethical approval: The study was approved by the Institutional Ethics Committee

\section{REFERENCES}

1. Ajayi A, Hellandendu J, Odekunle F. Sociodemographic correlates of breastfeeding practices among mothers in Kogi state, Nigeria. West African Journal of Nursing. 2011;22(1);28-37.

2. Malini D, Janell L. Maternal breastfeeding attitudes: association with breastfeeding intent and sociodemographics among urban primiparas. J Community Health. 2008;33(2);53-60.

3. Herta J, Bahl C, Martines U, Victoria S. Evidence on the long term effects of breastfeeding: systematic reviews and meta-analyses. Geneva Switzerland: 2007.
4. WHO. 2007. http//www.en.wikipedia.org/wiki/. Accessed 10/02/2012.

5. Celi A, Rich-Edwards J, Richardson M, Kleinman K, Gillman M. Immigration, Race/Ethnicity, Social and Economic factors as predictors of breastfeeding initiation. Arch Pediatr Adolesc Med. 2005;159(3):255-60.

6. Medical Records. University of Port Harcourt Teaching Hospital. 2012.

7. Dubois L, Girard M. Social determinants of initiation, duration and exclusivity of breastfeeding at the population level: the results of the Longitudinal Study of Child Development in Quebec (ELDEQ 1998-2002). J Public Health. 2003;94(4):300-5.

8. Sash N, Sheila M. State of science for practice to promote breastfeeding success among young mothers. NAWR A. 2014;14(3):112-8.

9. Kosamala-Anderson J, Wallace L. Breastfeeding works:the role of employers in supporting women who wish to breastfeed and work. Journal of Public Health. 2006;28(3):183-91.

10. Noble L, Hand I, Haynes D, McVeigh T, Kim M, Yoon J. Factors influencing initiation of breastfeeding among urban women. American Journal of Perinatology. 2003;20:477-83.

11. Li R, Darling N, Maurice E, Barker L, Grummer Strawn LM. Breastfeeding rates in the United States by characteristics of the child, mother, or family: The 2002 National Immunization Survey. Pediatrics. 2005;115(1):e31-e37.

12. Ryan A, Zhour W, Arensberg M. The effect of employment status on breastfeeding in the United States. Womenâ€ $€^{\mathrm{TM}_{\mathrm{S}}}$ Health Issues. 2006;16:243-51.

Cite this article as: Robinson-Bassey GC, Maureen FD, Rosemond IC. Factors influencing breastfeeding preparedness among primigravidae attending antenatal clinic, at university of Port Harcourt teaching hospital, Rivers state, Nigeria. Int J Reprod Contracept Obstet Gynecol 2016;5:1071-6. 